\title{
Statistical Analysis of Oceanic Rainfall Characteristics in the Baiu Season Utilizing TRMM PR Data
}

\author{
Yukari N. TAKAYABU \\ Center for Climate System Research, The University of Tokyo, Kashiwa, Japan \\ Research Institute for Global Change, Japan Agency for Marine-Earth Science and Technology, \\ Yokosuka, Japan \\ and \\ Kenta HIKOSAKA ${ }^{1}$
}

Center for Climate System Research, The University of Tokyo, Kashiwa, Japan

(Manuscript received 4 July 2008, in final form 9 December 2008)

\begin{abstract}
Temporal variations of rainfall characteristics over the ocean to the south of the Japan Archipelago during the Baiu season are quantitatively analyzed, and their relationships to the variations of environmental conditions are discussed. The Tropical Rainfall Measuring Mission (TRMM) Precipitation Radar (PR) data are utilized for the precipitation, upper-air observation data at six oceanic stations of the Japan Meteorological Agency (JMA), and the reanalysis data produced by JMA are utilized for the environmental data, to study the nine Baiu seasons from 1998 to 2006.

Calendar-day averaged time series of nine-year TRMM PR data show a significant increase of tall rain in the latter period of the Baiu season, which accompanies the destabilization of the environmental thermodynamic conditions. Utilizing the values of Convective Available Potential Energy (CAPE), Baiu periods are classified into the earlier-period type (EPT) days and the latter-period type (LPT) days, such that EPT/ LPT days are those with negative/positive CAPE anomalies from the entire Baiu-period average. Between the two periods, the convective rain ratio and the stratiform rain characteristics change significantly. In the EPT days, weak stratiform rain associated with the Baiu front is dominant and characterized by an intensity of $\sim 2.5 \mathrm{~mm} \mathrm{~h}^{-1}$ and a rain-top height (RTH) of $\sim 5 \mathrm{~km}$. In the LPT days, rain is dominated by cloud clusters along the Baiu front with larger contribution from the convective rain, associated with stronger and deeper stratiform rain characterized by $\sim 5.0 \mathrm{~mm} \mathrm{~h}^{-1}$ intensity and $7.0-7.5 \mathrm{~km} \mathrm{RTH}$.

Four rain types are classified with the rainfall characteristics obtained from TRMM PR data at 1 degree $\mathrm{x} 1$ degree grids, with the thresholds of convective rain ratio at $35 \%$ and rainfall intensity at $2.5 \mathrm{~mm}$ $\mathrm{h}^{-1}$. Type 1 represents the weak stratiform rain along the Baiu front, type 2 rain has well organized cloud clusters, and type 3-rain corresponds to relatively shallow convective rain often found under the influence of the subtropical high. The type-4-rain region can be interpreted as a temporally-varying mixture of rain
\end{abstract}

Corresponding author: Yukari N. Takayabu, Center for

Climate System Research, The University of Tokyo,

5-1-5 Kashiwanoha, Kashiwa, Chiba 277-8568, Japan

E-mail: yukari@ccsr.u-tokyo.ac.jp

1 Present affiliation of K. Hikosaka: Japan Weather

Association

(C2009, Meteorological Society of Japan 
types 1 and 2. Statistics of rainfall types and environmental conditions suggest that dominant rainfall characteristics may be diagnosed utilizing environmental variables such as the equivalent potential temperature at $1000 \mathrm{hPa}$ and the mean sea-level pressure.

\section{Introduction}

The early-summer rainy season in Japan is called "Baiu," a counterpart of the Chinese "Meiyu." In the Baiu season, a belt of subtropical moist air extends from south China to over the southern sea regions of Japan and brings a large amount of rain over Japan. Extreme precipitation is often observed, especially in the latter part of the Baiu season.

Hierarchical structures of the Baiu front are often described in various studies. For example, Ninomiya and Akiyama (1992) and Ninomiya and Shibagaki (2007) indicated that a cloud band associated with the Baiu front consists of coexisting synoptic-scale low pressure systems and meso- $\alpha$-scale (2000 to $200 \mathrm{~km}$ ) cloud systems. Meso- $\alpha$-scale cloud systems further consist of meso- $\beta$-scale (200 to $20 \mathrm{~km}$ ) and meso$\gamma$-scale $(20$ to $2 \mathrm{~km}$ ) precipitation systems. Extreme rain in the Baiu season is brought about either by a synoptic-scale disturbance (Ninomiya and Yamazaki 1979) or by meso-alpha scale disturbances along the Baiu front (Ninomiya et al. 1988a, b; Ninomiya and Shibagaki 2003).

Chen et al. (2004) utilized the preciptation data obtained from the Climate Prediction Center Merged Analysis Precipitation (CMAP) data to analyze the temporal variation of daily precipitation of the East Asian summer monsoon. They indicated that the average rainfall rate in the Japan region is about 6 $\mathrm{mm} \mathrm{day}{ }^{-1}$ in early to mid June, about $9 \mathrm{~mm} \mathrm{day}^{-1}$ in the last ten days, and 6 to $7 \mathrm{~mm} \mathrm{day}^{-1}$ in early to mid July. Although these results confirm that the rainfall amount varies in the Baiu season, there are no statistical studies examining the variations of rainfall characteristics accompanying the variations of rainfall amount.

Numerous studies have been devoted to describing characteristic structures of the Baiu front. Ninomiya (1984) compared the Baiu fronts with the polar fronts and indicated that the Baiu front is a subtropical front characterized with large gradients of specific humidity and of equivalent potential temperature, while a large gradient of the potential temperature characterizes the polar front. Kato et al. (2003) examined the structures of meridional vertical sections of the Baiu front utilizing numerical simulations. He emphasized the important role of a moist layer below $850 \mathrm{hPa}$ to the south of the Baiu front in providing moist air to as far as the northern edge of the Baiu front. He also pointed out that upper air to the south of the Baiu front is very dry and associated with a subsidence under an influence of the subtropical high, resulting in a strong convective instability and occasional extreme rain. More recently, Moteki et al. (2004a, b) indicated the existence of moist air with a continental origin from southern China, which bears another front between the moist air masses of continental origin and maritime origin.

While these studies examine the detailed structures of the Baiu front and associated cloud clusters that occasionally bring extreme precipitation, there are fewer studies that statistically examine the temporal variation of rain characteristics throughout the Baiu season.

Kato et al. (2007) conducted a statistical study of the level of neutral buoyancy (LNB) in the Baiu season utilizing the 25-year reanalysis data produced by JMA (JRA-25). With JRA-25 data, higher LNBs are diagnosed more frequently in July than in June, suggesting a larger potential for deeper convection and severer precipitation in the latter part of the Baiu season. However, we should remember that LNB is an index merely for the potential of convection height and not a necessary condition for actual convective precipitation. Furthermore, a substantial amount of precipitation also comes from stratiform rain during the Baiu season, which cannot be diagnosed with LNB frequencies.

The purpose of this study is to statistically examine the temporal variation of precipitation characteristics during the Baiu season and its relationship with the variation of the environmental conditions. To this end, we utilize three-dimensional precipitation data acquired with the Precipitation Radar (PR) installed on the Tropical Rainfall Measuring Mission (TRMM) satellite, for the Baiu seasons of 1998 to 2006. Previous studies indicated that TRMM PR data had a good potential to describe the rainfall character- 
istics. For example, Geng and Yamada (2007) utilized the TRMM PR data to study diurnal variations of the Meiyu/Baiu rain belt and found an interesting contrast of diurnal variations between the frontal zone and its side regions. In this study, we compare the spatial distributions of the rainfall characteristics and the environmental conditions and try to diagnose the rainfall type classifications with environmental conditions.

Section 2 describes the utilized data. Section 3 presents the analysis method. Analysis results are found in Sections 4 to 6. Finally, Section 7 provides the summary and conclusions.

\section{Data}

Precipitation data utilized in this study are obtained from the TRMM PR2A25 ver. 6 data. In these data, rain rates are provided in their original resolutions of $\sim 4.3 \mathrm{~km}$ in the horizontal direction and $250 \mathrm{~m}$ in the vertical direction up to $20 \mathrm{~km}$. The swath widths of PR are $215 \mathrm{~km}$ before the satellite reboost in August 2002 and $245 \mathrm{~km}$ after. Precipitation flags in PR2A25 data for each column are imported from the PR2A23 algorithm, which includes the classification of rain types into convective, stratiform, and other types of rain, together with the "rain certain" flag. Please note that "rain types" in PR2A23 differ from rain types we define later in this study. Since the near-surface precipitation data sometimes contain some errors, we utilize the 2 to $4 \mathrm{~km}$-level-mean rain rate, in place of the surface precipitation. The analysis period covers the nine Baiu seasons from 1998 to 2006. The "Baiu season" in each year is defined with Baiu onset and withdrawal dates declared by JMA (summarized in Table 1). The earlier dates for the onset in the Okinawa region and the later dates for the withdrawals in the Amami region are selected; 2031 orbits were utilized in this study analysis period.

The analysis region for TRMM data is depicted in Fig. 1 surrounded by a black line, which is an oceranic region around the Baiu front and can be roughly represented by six upper-air stations. In this study, we concentrate on the rain over the ocean, where we can obtain larger data samples than over the Japan Archipelago. For the analyses of the spatial distribution of rainfall characteristics and environmental conditions described in Section 6, PR2A25 precipitation data are composited into $1^{\circ} \times 1^{\circ}$ longitude and latitude grids for EPT days and for LPT days.

For meteorological data, we first utilized rawinsonde observation data at six JMA upper air stations, Hachijo-jima, Naze, Ishigaki-jima, Naha, Minami-
Table 1. Onset dates or withdrawal dates of the Baiu season in each year over the analysis region, defined as the earlier declaration date by JMA between Okinawa and Amami for the onset and later date between them for the withdrawal.

\begin{tabular}{|c|c|c|}
\hline Year & Onset date & Withdrawal date \\
\hline 1998 & April 25 & June 24 \\
\hline 1999 & May 09 & June 23 \\
\hline 2000 & May 17 & June 21 \\
\hline 2001 & May 06 & June 23 \\
\hline 2002 & May 08 & June 30 \\
\hline 2003 & May 13 & June 27 \\
\hline 2004 & May 05 & June 24 \\
\hline 2005 & May 02 & June 27 \\
\hline 2006 & May 11 & June 22 \\
\hline
\end{tabular}

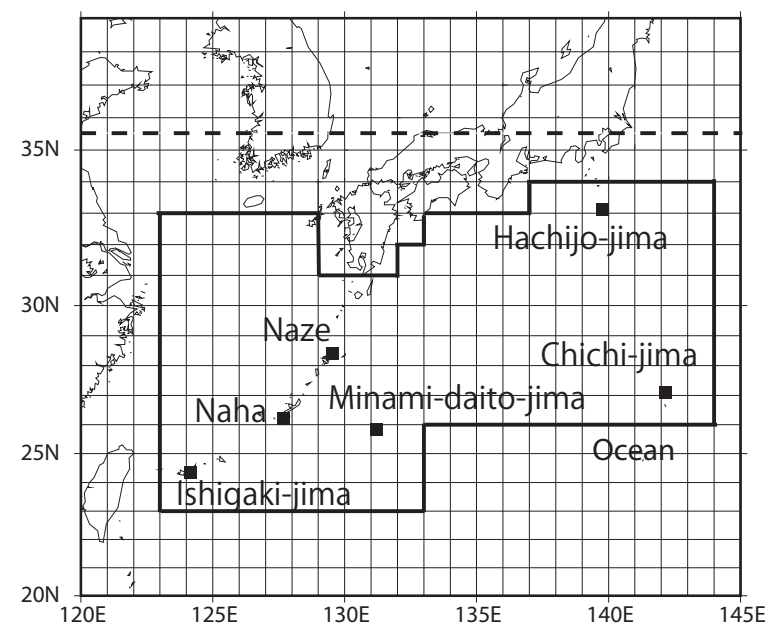

Fig. 1. Analysis region over the ocean surrounded by the bold black line. Black rectangles indicate the locations of upperair stations. TRMM PR data are available to the south of $36.5^{\circ} \mathrm{N}$ (indicated by the thick, dashed line). 
daito-jima, and Chichi-jima, indicated in Fig. 1 with black rectangles. We utilized twice daily (0900 JST, and $2100 \mathrm{JST}$, where JST=UTC+9 hours) upper air observation data at 17 specified levels $(1000,925,900$, $850,800,700,600,500,400,350,300,250,200,175$, 150,125 , and $100 \mathrm{hPa}$ ). Altitudes, temperature, relative humidity, wind direction, and wind speed are utilized.

To achieve better horizontal resolution of meteorological data, we also utilized the 25-year JRA-25 data for the Baiu seasons in 1998 to 2004 and succeeding JMA Climate Data Assimilation System (JCDAS) data for those in 2005 and 2006. JCDAS is the objective analysis data set produced with the same procedures as the JRA-25 data. Both datasets are provided in horizontal grids of $1.25^{\circ} \times 1.25^{\circ}$ at 23 pressure levels $(1000,925,850,700,600,500,400,300,250$, $150,100,70,50,30,20,10,7,5,3,2,1$, and $0.4 \mathrm{hPa}$ ), among which we utilized only up to $100 \mathrm{hPa}$. When these analysis data are analyzed with the TRMM PR $1^{\circ} \mathrm{x} 1^{\circ}$ data, the nearest grid of the $1.25^{\circ}$ resolution data are selected.

We also utilized infrared images of the Japanese Geostationary Satellite, obtained from Kochi University's "Weather Home" at http://weather. is.kochi-u.ac.jp/, and weather maps obtained from the CD-ROM "JMA weather charts," issued by the Japan Meteorological Buisiness Support Center.

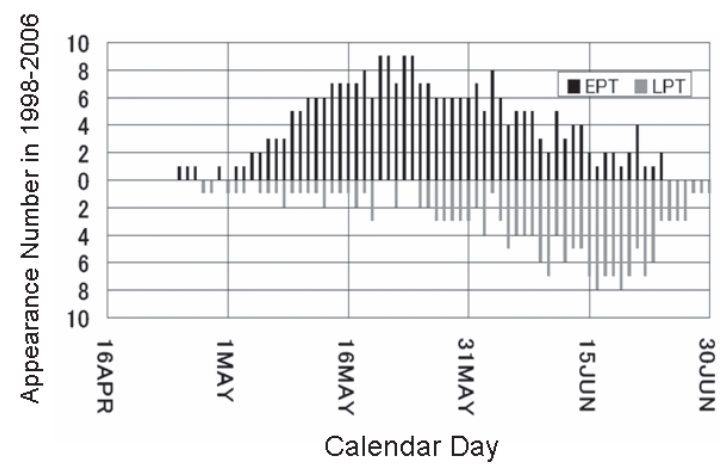

Fig. 2. Appearance frequencies of the EPT (upper) and LPT (lower) days classified by the anomalies of regional-mean CAPE values in nine years (1998 to 2006). See text for the details of classification.

\section{Methodology}

First, we examine the evolution of the rain and the environments during the Baiu season with their temporal variations averaged in calendar days.

Second, we examine the differences in rainfall characteristics and environmental conditions between the earlier and latter conditions of the Baiu season. We classify the earlier and latter period environmental conditions in terms of CAPE. We first calculate a CAPE value for each day, averaged over six upperair observations in the analysis region (CAPE6). We then obtain a mean value of CAPE6 for all Baiu seasons from 1998 to 2006 (CAPE6-M), which is 350.3 $\mathrm{J} \mathrm{kg}^{-1}$. The thermodynamic conditions for an individual day are determined from the sign of the anomaly of CAPE6 from CAPE6-M. To calculate CAPE, the lowest level is selected for the starting level of the parcel since previous studies indicated that the diagnosed cloud base is not too sensitive to the selection of the air at 900 to $1000 \mathrm{hPa}$ levels (Takayabu et al. 2006), so that mostly $1000 \mathrm{hPa}$ is selected. When the level of free convection (LFC) is not diagnosed, CAPE is set to zero. Figure 2 presents the number frequencies of days with below-average CAPE6 values (CAPE6 $\leqq$ CAPE6-M; upper part) and with aboveaverage CAPE6 values (CAPE6 > CAPE6-M; bottom part). Below-average-CAPE6 days are more frequently found in the earlier part of the Baiu season, while above-average days are found in the latter part. This gradual increase of CAPE6 values is associated with seasonal northward migration of a high SST region near the Baiu front, which gradually destabilizes the target region. We hereafter call the former days the earlier-period type (EPT) days, and the latter days the latter-period type (LPT) days.

\section{Area-average rainfall characteristics and environment}

Figure 3a presents a nine-year calendar-mean time series of seven-day running-mean contributions to the surface precipitation assigned to every $250 \mathrm{~m}$ raintop height (RTH) obtained from TRMM PR data. Summing this value over 80 levels of PR yields the surface rain rate. RTH is defined at each PR2a25 rainfall pixel as the highest level where a rainfall rate exceeding $0.5 \mathrm{~mm} \mathrm{~h}^{-1}$ is observed, under the condition that the rain rates below that level are not undefined. Black arrows indicate onset dates and withdrawal dates for each year as defined in Section 2, and the black contour indicates the $99 \%$ significance values 


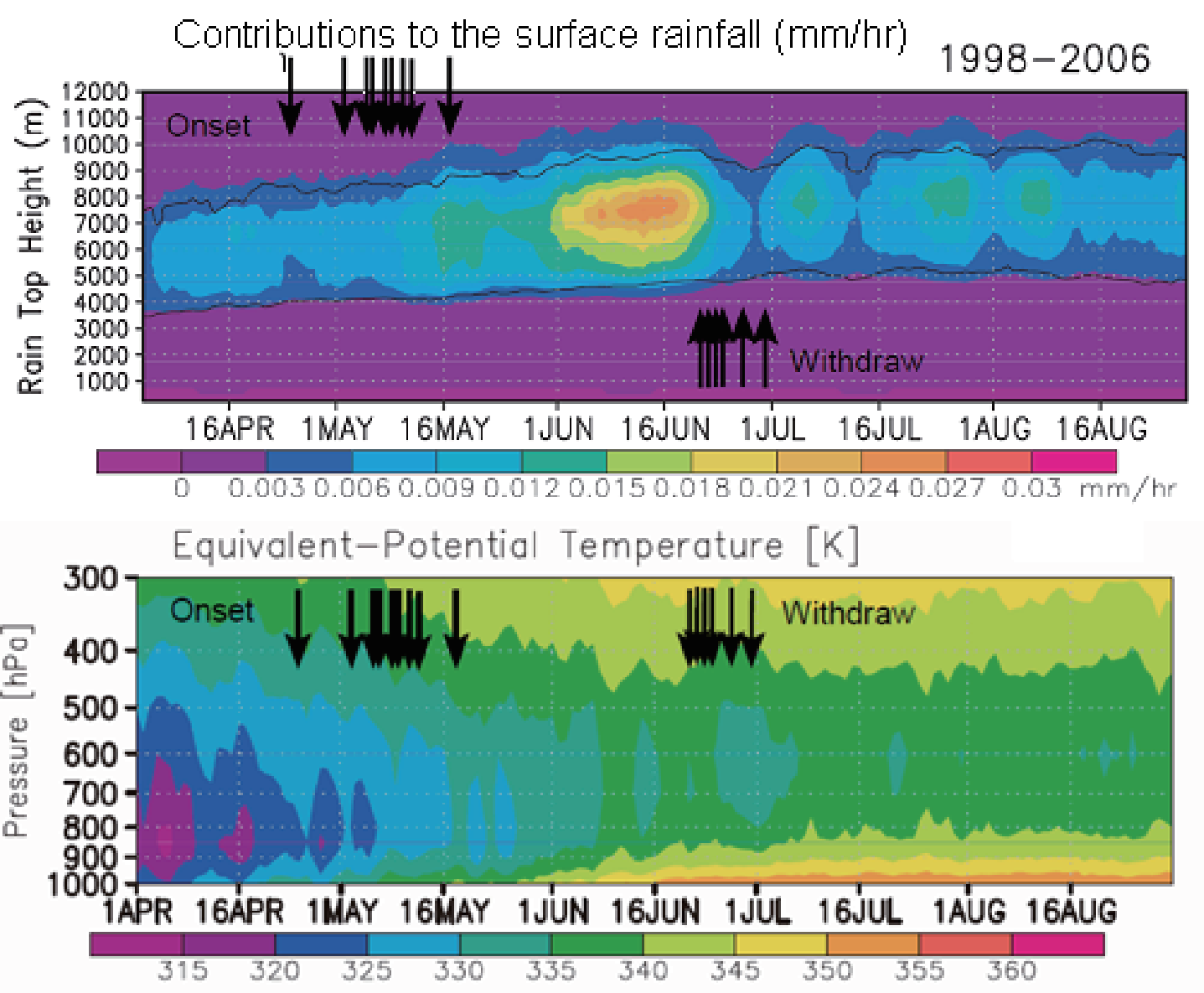

(b)

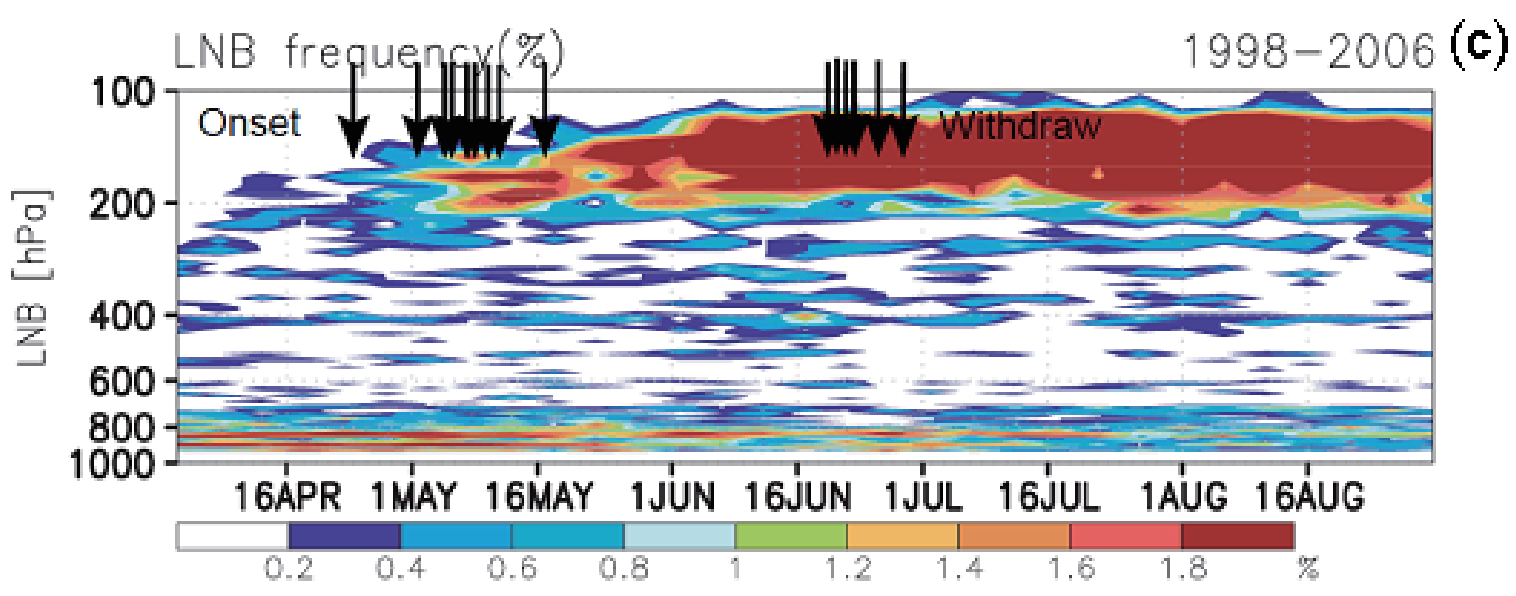

Fig. 3. Time series of nine-year calendar-mean seven-day running-mean surface precipitation assigned to rain-top heights (a), area-mean equivalent potential temperature profile (b), and appearance frequency of the levels of neutral buoyancy (LNB) (c). Black arrows indicate onset days and withdrawal days for each year declared by JMA, and black contour in (a) indicates the $99 \%$ significance level in terms of the anomalous surface rainfall contributions in the total surface rainfall. 
in terms of the anomalous surface rainfall contributions in the total surface rainfall. When we focus on the significant region, we note that taller rain gradually increases thoughout the Baiu season. In particular, contributions from the rainfall with $8 \mathrm{~km}$ or higher RTH increase gradually from early May to the middle of June. In contrast, the rainfall contribution from the mid-level RTH $(\sim 4 \mathrm{~km})$ around the bottom part of the significant region decreases throughout the Baiu season. Considering that taller convective rain is basically more intense (e.g., Takayabu 2002), this figure suggests that, as an area and calendar-day average, intense rainfall increases in the latter period of the Baiu season.

Next, we examine the calendar-day average time series of the equivalent potenital temperature $(\theta \mathrm{e})$ and the LNB frequencies calculated from the upper-air station data. Equivalent potential temperature profiles (Fig. 3b) indicate increasing lower tropospheric convective instability thoughout the Baiu season, and the lowest-level $\theta$ e exceeds $340 \mathrm{~K}$ from June onwards. While LNBs higher than $200 \mathrm{hPa}$ are diagnosed almost during the entire Baiu season, their frequency (Fig. 3c) increase significantly from June. This apparent increase of very high LNB coincides well with the timing that the lowest-level $\theta \mathrm{e}$ exceeds $340 \mathrm{~K}$, as well as with the contribution from rainfall with RTH above $9 \mathrm{~km}$ becoming significant. From April to May, a dominance of low-level LNBs at around 850 to 900 $\mathrm{hPa}$ is observed, which may relate to shallow convection as mentioned in Kato et al. (2007).

\section{Rainfall characteristics in EPT days and LPT days}

In this section, average rainfall characteristics and the atmospheric stratification are examined following the definitions for the EPT days and for the LPT days in terms of CAPE. Figure 4 depicts the average atmospheric thermodynamic structure for EPT days and LPT days calculated from the upper-air station data. In the EPT days, the lower troposphere below $700 \mathrm{hPa}$ is relatively dry and conditionally stable although the lower troposphere below $800 \mathrm{hPa}$ is convectively unstable as diagnosed with $\theta \mathrm{e}$. LNB at $900 \mathrm{hPa}$ is diagnosed on average. In contrast, in LPT days, clear conditional instability is also found and LNB at $200 \mathrm{hPa}$ is diagnosed on average, in addition to the increased lower tropospheric convective instability. This contrast of these average profiles clearly indicates that the environmental conditions in LPT days are more favorable for taller convection compared to those in EPT

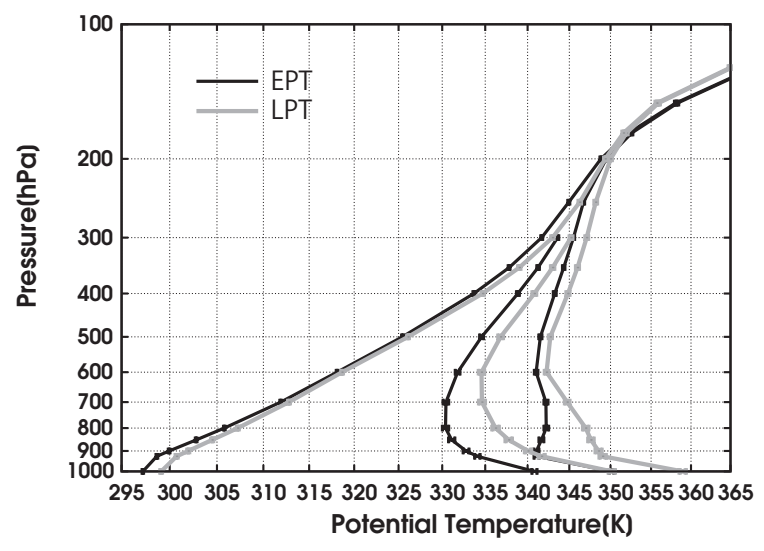

Fig. 4. Average atmospheric thermodynamic structure for EPT days (black) and LPT days (gray) obtained from the oceanic station data. Three lines in each color indicate potential temperature, equivalent potential temperature, and saturated equivalent potential temperature from left to right. Horizontal ticks at each level indicate the $95 \%$ significance intervals from the Student-t test.

days.

Figure 5 plots histograms of the convective rain and the stratifrorm rain for EPT days and LPT days separately, in terms of the rain intensity in $\mathrm{dBR}$ where $\mathrm{dBR}=10 * \log _{10}$ (rain rate).

Stratiform rain contributions to the surface precipitation more than double the convective rain contributions in both EPT and LPT days. However, the convective rain contribution increases significantly in LPT days compared to EPT days.

For both periods, the peak intensity for the convective rain contribution is found at around 14 to $15 \mathrm{dBR}$, which corresponds to 25 to $32 \mathrm{~mm} \mathrm{~h}^{-1}$, while there are two peaks in the stratiform rain at around $7 \mathrm{dBR}(5$ $\left.\mathrm{mm} \mathrm{h}^{-1}\right)$ and at around $4 \mathrm{dBR}\left(2.5 \mathrm{~mm} \mathrm{~h}^{-1}\right)$. Although the separation of the latter two peaks for the stratiform rain contribution is not significant, the decrease of the weaker peak contribution at $4 \mathrm{dBR}$ in LPT days is statistically significant, suggesting the existence of two kinds of stratiform rain. We also note that a contribution of relatively stronger ( $>8 \mathrm{dBR}$ ) stratiform rain increases in LPT days, although it is not as significant as the decrease of the weaker stratiform rain.

Rain contribution is also examined in terms of the 

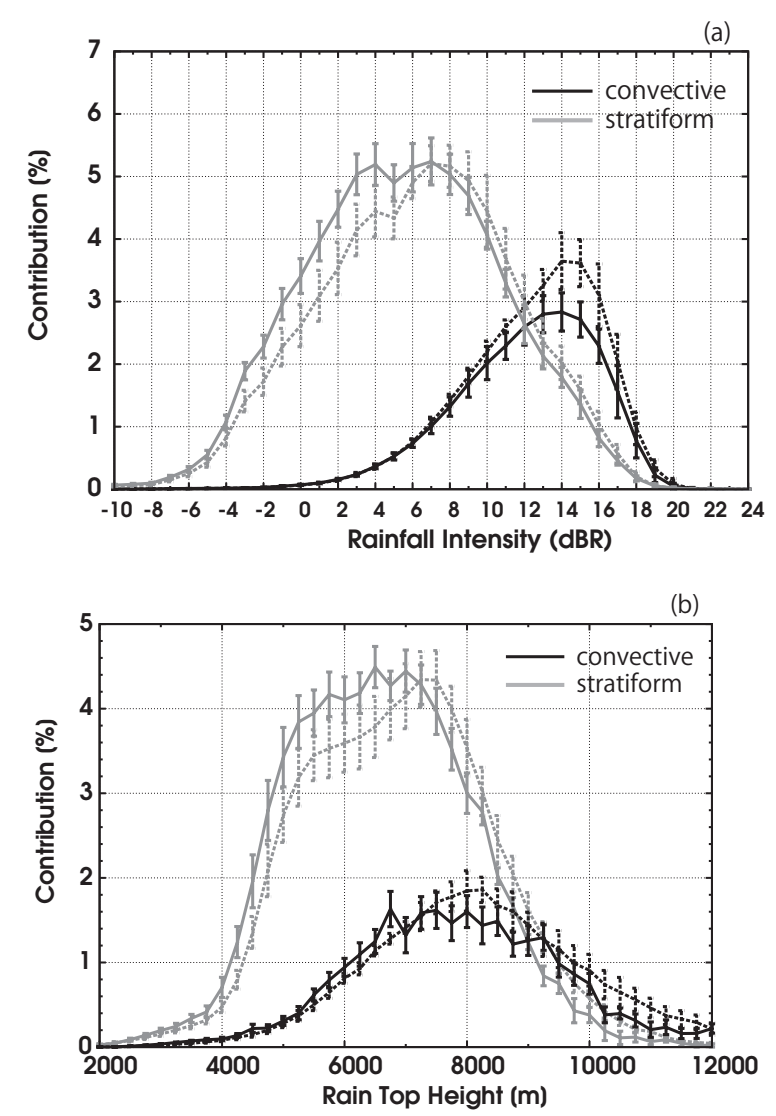

Fig. 5. Histograms of convective rain (black) and stratiform rain (gray) contributions to the total rain over the ocean in terms of the rain intensity in dBR (a) and the rain-top height (b). Solid lines are for EPT days and dashed lines for LPT days. Vertical ticks indicate the 95\% significance intervals from the Student-t test.

RTH in Fig. 5b. The largest contribution for the convective rain is from the rain with an RTH of around 8 $\mathrm{km}$, while that for the stratiform rain is from an RTH of 7 to $7.5 \mathrm{~km}$. There is a secondary peak for the stratiform rain at around $5.5 \mathrm{~km}$, especially for EPT days. The latter peak diminishes in LPT days, suggesting its correspondence with the weaker stratiform rain peak at $\sim 4 \mathrm{dBR}$ found in Fig. 5a. The convective rain contribution increases in LPT days for rain with RTH exceeding $7 \mathrm{~km}$.

Since some characteristic peaks were found in pre- vious histogram analyses, we next examine some typical cases of EPT and LPT rainfall, subjectively selected by looking at the Japanese Geosynchronous Meteorological Satellite infrared (GMS IR) images and weather charts for the respective day types, to see what meteorological phenomena these statistical peaks represent. Figure 6 depicts the sample cases for weather maps, the GMS IR images, TRRM $\mathrm{PR}$ rain rates, and convective rain ratio derived from the TRMM PR data for an EPT day and an LPT day. The left panels of Fig. 6 are for June 2, 2001, a typical EPT day. To the south of the Japan Archipelago, the Baiu front extends from southwest to northeast and is associated with a cloud band. The surface rain rate observed with TRMM PR is dominated by rain areas with rates less than $6 \mathrm{~mm} \mathrm{~h}^{-1}$. The convective rain ratio is generally less than $20 \%$, with only some convectively dominant rain. The right panels of Fig. 6 are for June 8, 1999, a typical LPT day. The Baiu front extends southwestward from a surface low found to the northeast of the Japan Archipelago. In the GMS IR image, a meso- $\alpha$-scale cloud cluster is observed to the south of Kyusyu Island along the Baiu front with a brighter leaf-shaped image. The TRMM PR rain rate indicates an intense rain band around this cloud cluster with a rain rate exceeding $20 \mathrm{~mm} \mathrm{~h}^{-1}$. A band of convective rain with the convective rain ratio exceeding $60 \%$ and an accompanying wide stratiform rain area are observed, consistent with the characteristics of a well organized cloud cluster.

Next, we selected six typical cases of rainy days observed with TRMM PR from EPT and LPT days and examined their rain characteristics in histograms. Figure 7 presents the histograms of rainfall contribution in terms of the rain intensity for EPT and LPT days. Clear differences in rain characteristics are observed between them. The stratiform rain contribution is dominant ( $83 \%$ ) for EPT days; its peak contribution is found at $4 \mathrm{dBR}\left(\sim 2.5 \mathrm{~mm} \mathrm{~h}^{-1}\right)$, with a second peak at $7 \mathrm{dBR}\left(\sim 5 \mathrm{~mm} \mathrm{~h}^{-1}\right)$. These two peaks correspond to those found in the nine-year statistics in Fig. 5. For convective rain, a contribution from 9 to $13 \mathrm{~dB}$ $\mathrm{R}\left(8\right.$ to $\left.20 \mathrm{~mm} \mathrm{~h}^{-1}\right)$ is dominant, which is weaker than the long-term statistics.

For typical LPT days, the stratiform rain contribution decreases to $55 \%$. It is notable that for LPT days, only a peak at 7 to $8 \mathrm{dBR}\left(5\right.$ to $6.3 \mathrm{~mm} \mathrm{~h}^{-1}$ ) is found for the stratiform rain contribution and the weaker peak at $4 \mathrm{dBR}$ is diminished. The contribution of convective rain becomes much larger than in EPT days, and the peak intensity increases to $15 \mathrm{dBR}(\sim 32 \mathrm{~mm}$ 
(a)
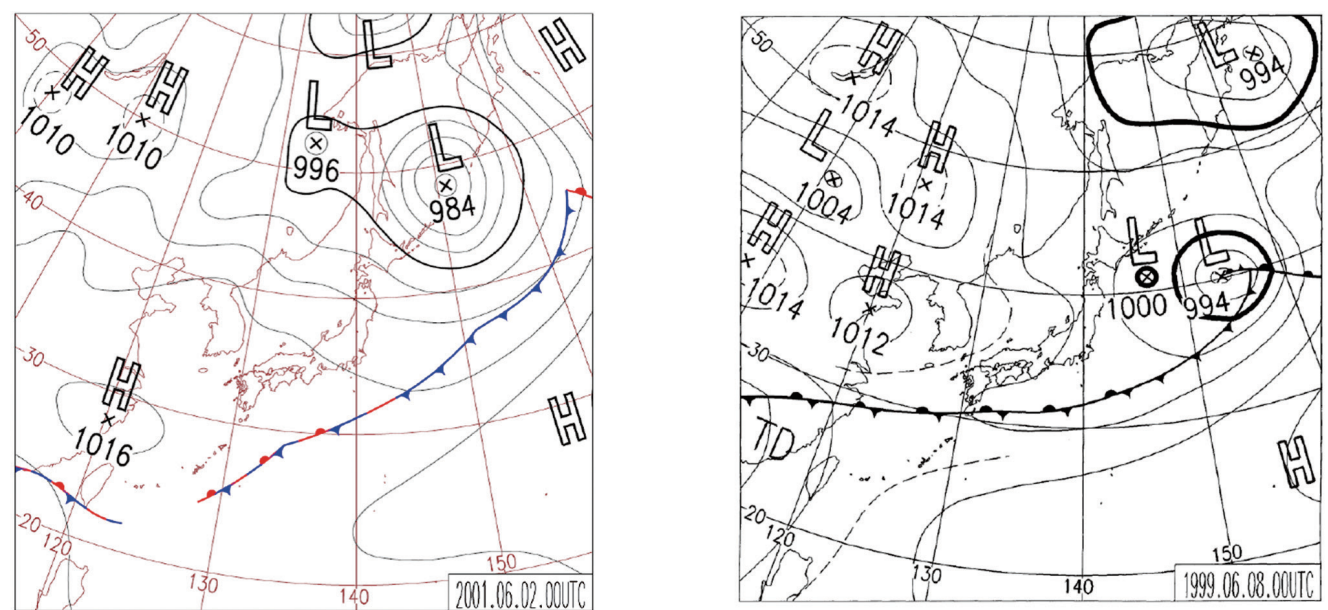

(b)
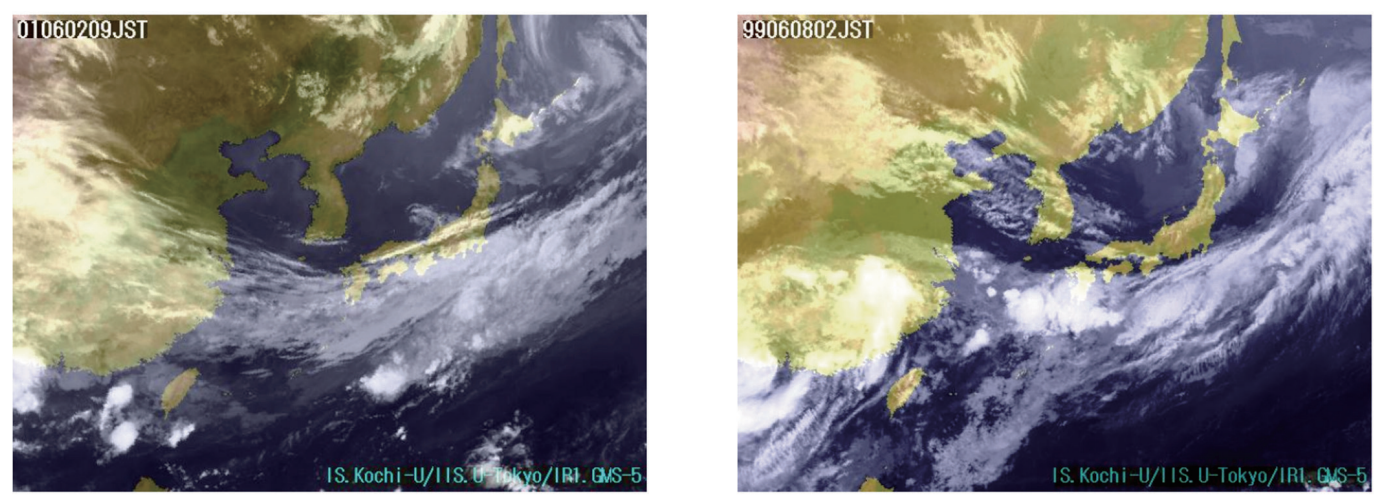

(c)
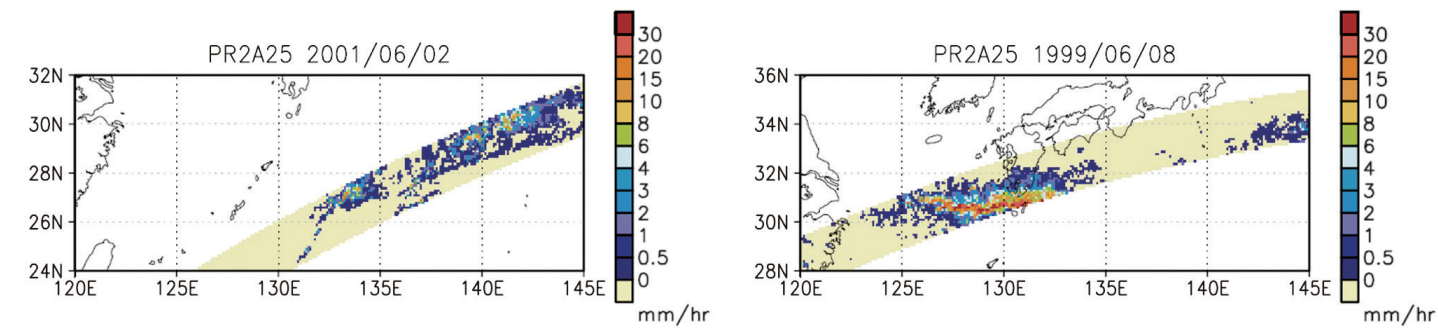

(d)
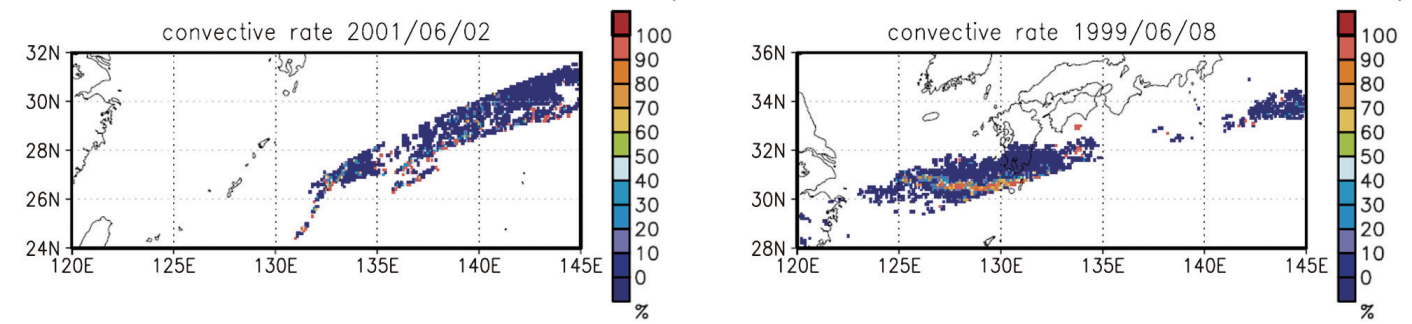

Fig. 6. Sample cases for an EPT day, June 2, 2001 (left) and for an LPT day, June 8, 1999 (right). Panels are for weather charts (a), GMS IR images (b), rain rate (c), and the convective rain ratio in $0.1 \mathrm{deg} \mathrm{x}$ 0.1 deg grids (d). Values for (c) and (d) are obtained from TRMM PR2A25 data. 


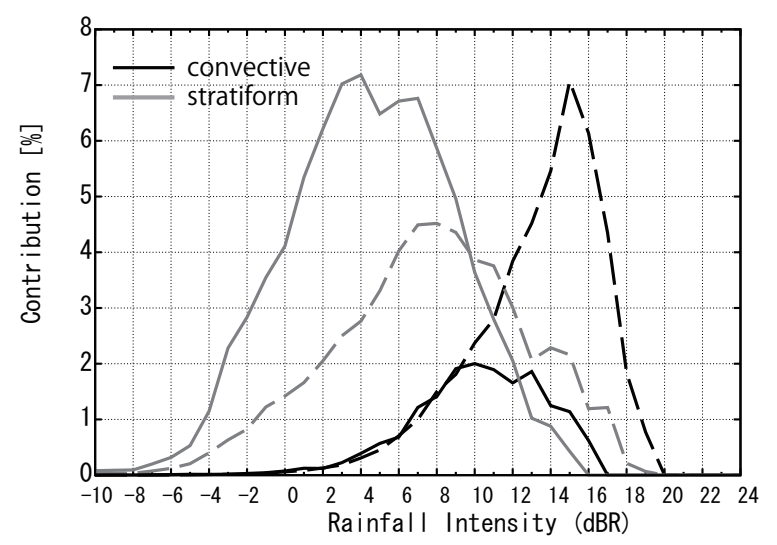

Fig. 7. Same as Fig. 5a but for six typical cases each for EPT days (solid lines) and LPT days (dashed lines). Significance tests are omitted for this figure.

$\left.\mathrm{h}^{-1}\right)$. Comparing histograms with IR images for several cases indicates that the weaker peak of $\sim 4 \mathrm{dBR}$ in stratiform rain contribution found in Fig. 5 corresponds to weak frontal stratiform rain typically found in EPT days, while the stronger peak of 7 to $8 \mathrm{dBR}$ stratiform rain is a contribution from deep stratiform rain associated with cloud clusters that characterize rain in LPT days but also exist in EPT days.

\section{Spatial distributions of rainfall character- istics and environmental conditions}

The statistical results in Fig. 5 and the case studies in Figs. 6 and 7 indicate temporal variations of rainfall characteristics. Rainfall in EPT days is characterized by weak stratiform rain along the Baiu front, but that in LPT days is characterized by cloud clusters organized with the convective rain. This section examines spatial distributions of rainfall characteristics in order to relate them to the environmental conditions.

Figure 8 depicts map distributions of convective rain ratio (CRR) versus the total rain (a), unconditional mean rain rate (b), rain-top heights for convective rain (c), and rainfall intensity (d) averaged for EPT days. Here, CRR is obtained as the summation of the convective rain amount divided by the total rain amount for each $1^{\circ} \times 1^{\circ}$ grid for EPT days. Solid and dashed contour lines are for average equivalent potential temperature $(\theta \mathrm{e})$ at $1000 \mathrm{hPa}$, and for the mean sea-level pressure (MSLP), respectively. Values of $\theta \mathrm{e}_{1000 \mathrm{hPa}}$ are calculated for each day at each grid and averaged for all EPT days. The convective rain ratio (Fig. 8a) exhibits a clear meridional contrast divided by the $340 \mathrm{~K} \theta \mathrm{e}$ contour around $26^{\circ} \mathrm{N}$, with values less than $25 \%$ dominant to the north and those exceeding $40 \%$ dominant to the south. The unconditional mean rain-rate distribution indicates that a primary rain region extends from the northern stratiform rain region to the southern convective rain region. It is interesting that, while the rain intensity is greater to the south of the $340 \mathrm{~K} \theta \mathrm{e}$ line, the convective rain-top height is not necessarily greater for the southern part, and it is less intense in the eastern part of the map where MSLP exceeds $1012 \mathrm{hPa}$.

Figure 9 depicts average rain characteristics of LPT days. As for the convective rain contribution (Fig. 9a), the boundary of the stratiform-dominant rain region and the convective-dominant rain region migrates northward in association with the northward migration of the $340 \mathrm{~K} \theta \mathrm{e}$ line. Note that in this figure, however, the boundary coincides better with a slightly higher $\theta \mathrm{e}$ contour as $343 \mathrm{~K}$. The primary rain region is mostly found in the convective rain dominant region, although straddling the convective-dominant region and the stratiform-dominant region. The primary intense rain area in this period is found to the south of the $340 \mathrm{~K} \theta \mathrm{e}$ contour and to the west (lower part) of the $1010 \mathrm{hPa}$ MSLP contour. To the east (higher part) of the $1010 \mathrm{hPa}$ MSLP contour, the convective rain contribution is large, but the total precipitation, convective rain-top height, and rain intensity are all small, indicating the suppression of rain activity by the subsidence accompanying the subtropical high.

By trial and error, based on the above results, we empirically classified the rainfall into four types with two indices as the convective rain ratio (CRR) and the rainfall intensity (RI) as follows:

Type $1 \mathrm{CRR} \leqq 35 \%, \mathrm{RI} \leqq 2.5 \mathrm{~mm} \mathrm{~h}^{-1}$

Type 2 CRR $>35 \%, \mathrm{RI}>2.5 \mathrm{~mm} \mathrm{~h}^{-1}$

Type $3 \mathrm{CRR}>35 \%, \mathrm{RI} \leqq 2.5 \mathrm{~mm} \mathrm{~h}^{-1}$

Type 4 CRR $\leqq 35 \%, \mathrm{RI}>2.5 \mathrm{~mm} \mathrm{~h}^{-1}$

Figure 10 depicts the distribution of the four diagnosed rain types for EPT days and LPT days. There is a clear shift of dominant rain types between the two periods. While type 1 spreads over the analysis region in EPT days, type 2 dominates the western part of the analysis region in LPT days. Type 4 rain regions are distributed near the center of the primary rain region, and sandwiched by type 1 and type 2 regions. Type 3 rain regions are found south of the type 2 rain and extend northward in LPT days with the northward shift of the Baiu front. The definition and the distribution 

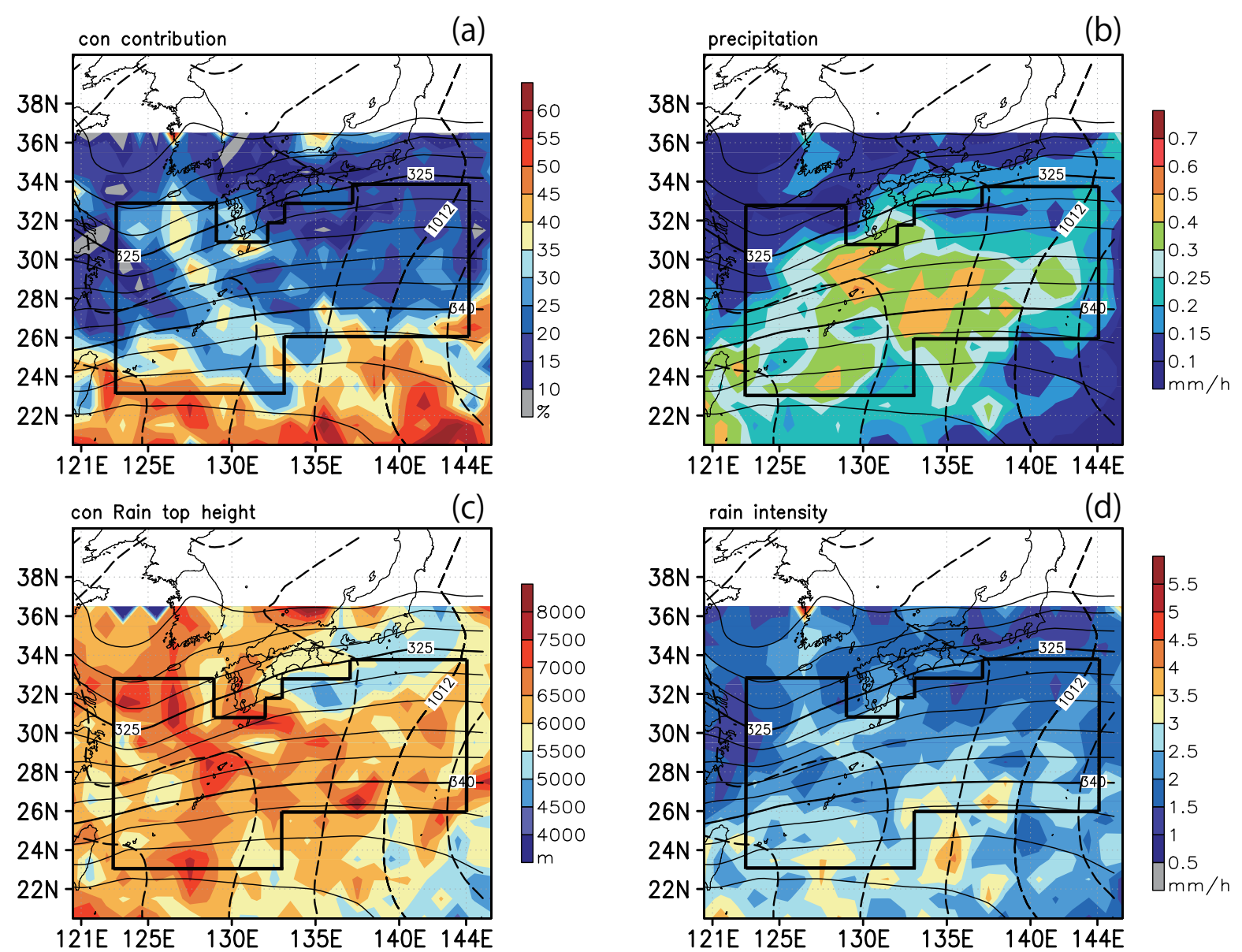

Fig. 8. Rainfall characteristics averaged for EPT days over the ocean obtained from TRMM PR2A25 data. Color shades in each panel are for convective rain ratio (a), unconditional mean rain rate (b), rain-top heights for convective rain (c), and average rainfall intensity (conditional mean rain rate) (d). Contours in solid and dashed lines are for average equivalent potential temperature at $1000 \mathrm{hPa}$ with $3 \mathrm{~K}$ intervals and for the mean sea-level pressure with $1 \mathrm{hPa}$ intervals. The ocean analysis region for Figs. 2-5 is also indicated with a bold black line.

imply that type 1 represents the weak stratiform rain along the Baiu front, type 2 rain is associated with the well organized cloud clusters, and type 3 rain corresponds to relatively shallow convective rain often found under the influence of the subtropical high. The type 4 rain region can be interpreted as a temporally-varying mixture of stratiform rain along the Baiu front (type 1) and the well organized cloud clusters (type 2).

Next, we compare the environmental conditions for these four rain types in order to examine what controls the rain type distribution. Figure 11 plots histo- grams of the occurrences of the four rain types versus equivalent potential temperature at $1000 \mathrm{hPa}\left(\theta \mathrm{e}_{1000}\right.$ $\left.{ }_{\mathrm{hPa}}\right)$, lower tropospheric convective instability $\left(\theta \mathrm{e}_{1000 \mathrm{hPa}}\right.$ $\left.-\theta \mathrm{e}_{700 \mathrm{hPa}}\right)$, and MSLP. To generate Fig. 11, we calculated CRR and RI for each day at $1^{\circ} \times 1^{\circ}$ grid boxes with TRMM PR data and determined a rain type for each box and each day. We then used the nearest-grid analysis data in a $1.25^{\circ} \times 1.25^{\circ}$ grid box to relate the rain type to environmental variables. Type 1 rain is mostly found over the region with $\theta \mathrm{e}_{1000 \mathrm{hPa}}$ values below $345 \mathrm{~K}$. Type 2 and type 3 are mostly found where $\theta \mathrm{e}_{1000 \mathrm{hPa}}$ exceeds $345 \mathrm{~K}$, with peaks at $352 \mathrm{~K}$ (type 2) 

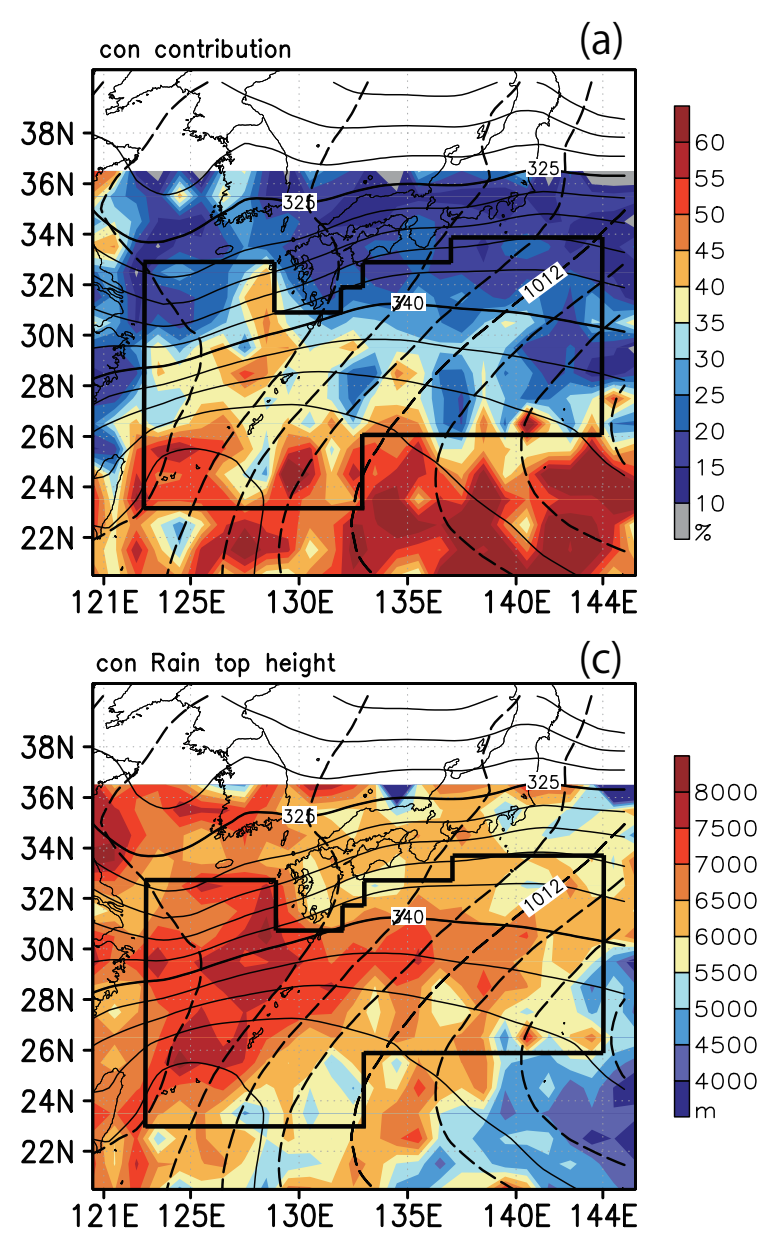
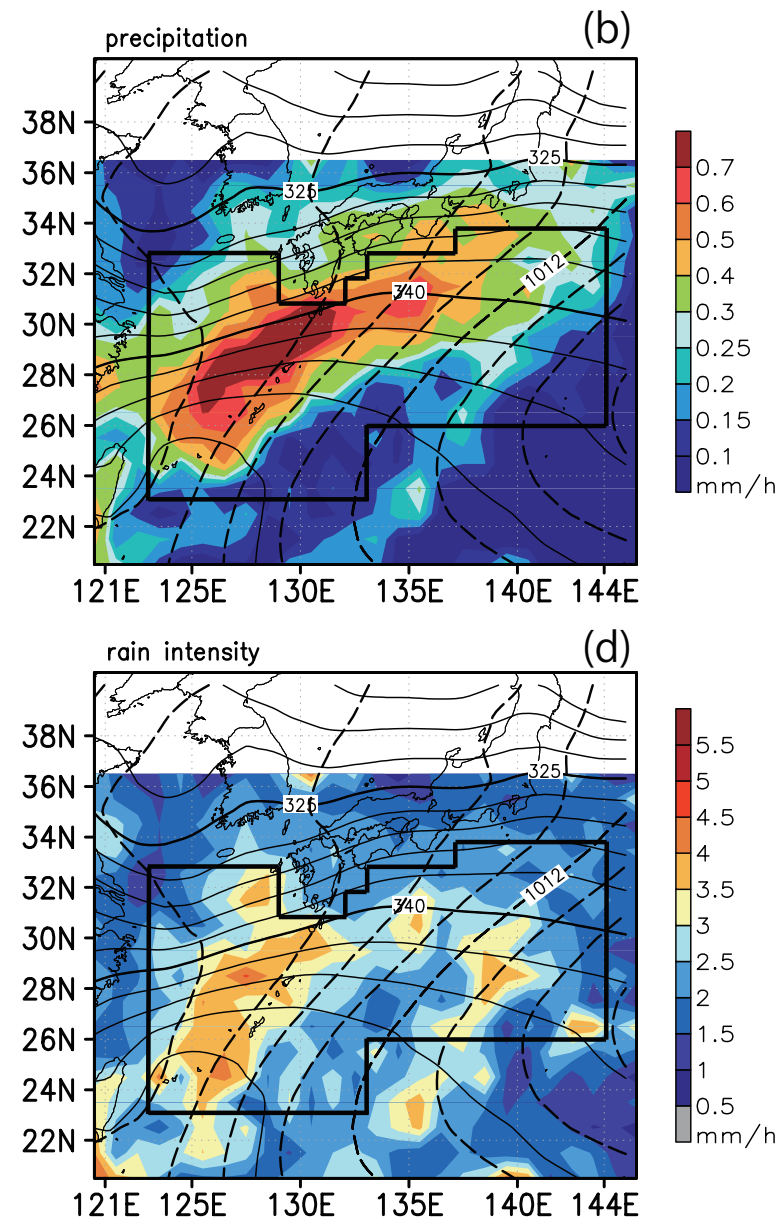

Fig. 9. Same as Fig. 8 but for LPT days.

and $350 \mathrm{~K}$ (type 3). Rain type 4 has a peak at around $347 \mathrm{~K}$ that exceeds the $345 \mathrm{~K}$ threshold, but its histogram also spreads widely below $345 \mathrm{~K}$. With the lower tropospheric instability, type 2 and type 3 are more clearly separated from type 1 and type 4 , in the sense that the former two types are more convectively unstable than the latter two types. The histograms are divided somewhere around $14 \mathrm{~K}(300 \mathrm{hPa})^{-1}$. The last panel is for the MSLP. Only type 3 stands out from the rest, and it is confirmed that convective and relatively weak type 3 rain is convective rain under the influence of the subtropical high. Generally speaking, however, absolute values of MSLP are not really meaningful. It may be better to consider a method to include the information of MSLP spatial variations, which is left for a future work.

The above analysis suggests the feasibility of diag- nosing rainfall types in terms of indices for environmental conditions.

\section{Summary and conclusions}

Temporal variations of rainfall characteristics over the ocean to the south of the Japan Archipelago during the Baiu season were quantitatively analyzed and their relationships to the variations of environmental conditions discussed. TRMM PR data were utilized for the precipitation, and upper-air observation data at six JMA oceanic stations and JMA reanalysis data were utilized for the environmental data, to study the nine Baiu seasons from 1998 to 2006.

Calendar-day averaged time series of nine-year TRMM PR data show a significant increase of tall rain in the latter period of the Baiu season, accompanied by the destabilization of the environmental ther- 

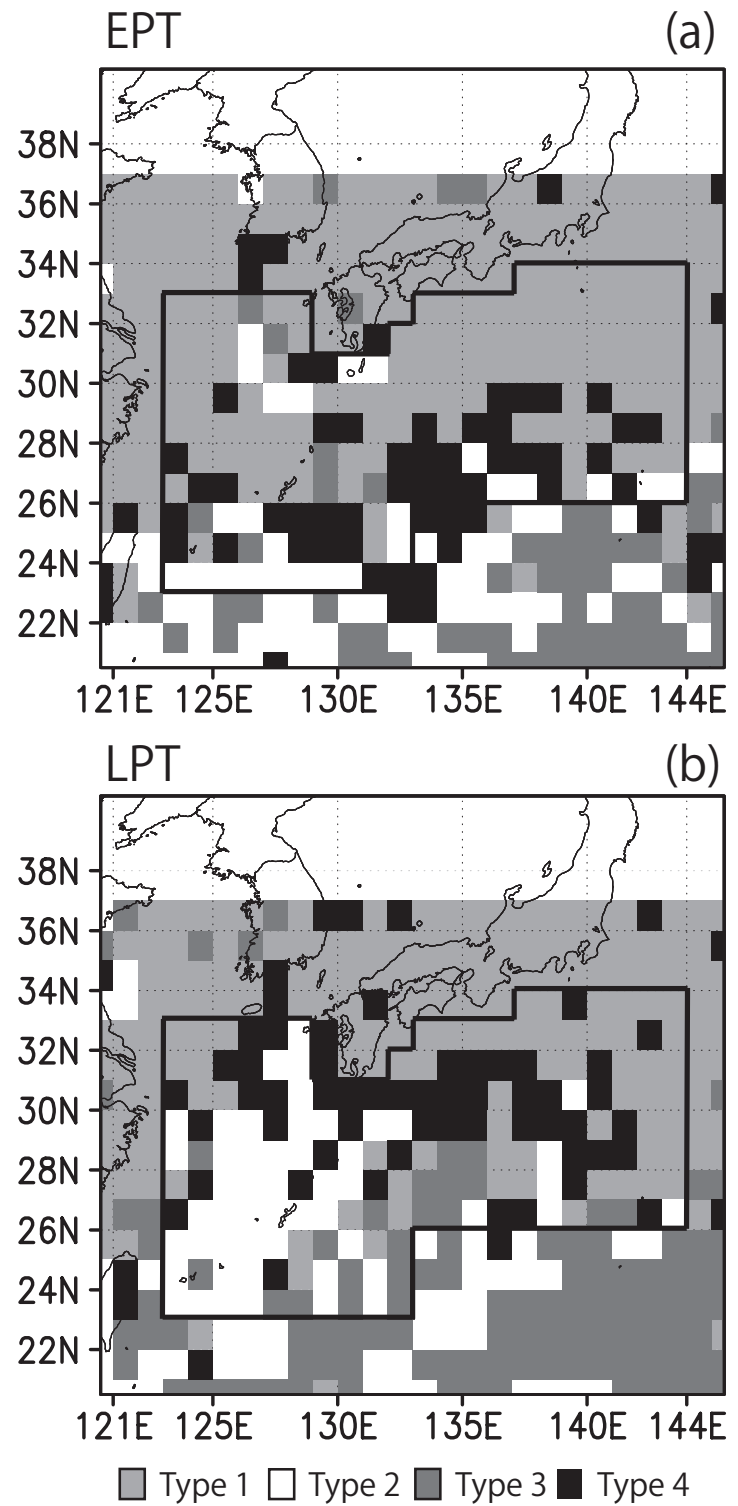

Fig. 10. Classifications of rainfall types for EPT days (a) and LPT days (b). Thick solid line indicates the ocean analysis region for Figs. 2 to 5. See text for details.
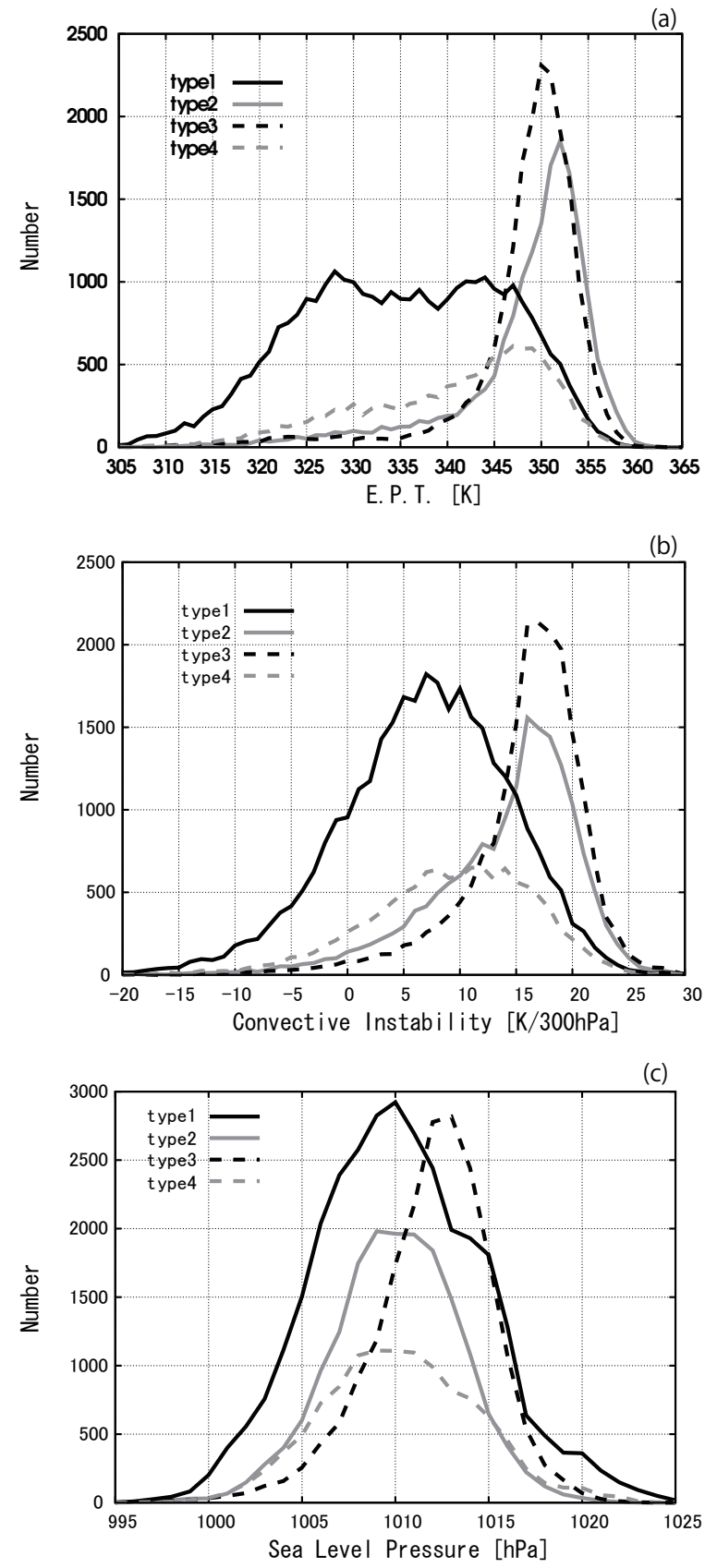

Fig. 11. Histograms of the environmental conditions for four rain types. (a) Equivalent potential temperature at $1000 \mathrm{hPa}\left(\theta \mathrm{e}_{1000 \mathrm{hPa}}\right)$. (b) Lower tropospheric convective instability $\theta \mathrm{e}_{1000 \mathrm{hPa}}$ $-\theta \mathrm{e}_{700 \mathrm{hPa}}$. (c), MSLP. Black solid lines are for type 1, gray solid lines for type 2 , black dashed lines for type 3 , and gray dashed lines for type 4 . 
modynamic conditions. Utilizing the values of CAPE, Baiu periods were classified into EPT days and LPT days; such that EPT (LPT) days have negative (positive) CAPE anomalies from the entire Baiu-period average. Some significant differences in rainfall characteristics between these two periods were identified. First, the convective rain ratio increases in LPT days as expected from the destabilization of the atmosphere. Second, significant differences in the stratiform rain characteristics were observed with histogram statistics. In EPT days, weak stratiform rain associated with the Baiu front dominated and was characterized by an intensity of $\sim 2.5 \mathrm{~mm} \mathrm{~h}^{-1}$ and an RTH of $\sim 5 \mathrm{~km}$. In LPT days, rain is dominated by cloud clusters along the Baiu front with more contribution from the convective rain and associated with stronger and deeper stratiform rain characterized by $\sim 5.0 \mathrm{~mm}$ $\mathrm{h}^{-1}$ intensity and 7.0 to $7.5 \mathrm{~km} \mathrm{RTH}$.

Rain types averaged in EPT and LPT days were classified based on rainfall characteristics in terms of the convective rain ratio and rainfall intensity. Comparing rainfall type distributions with the environmental conditions, lower tropospheric destabilization that can be diagnosed with $\sim 340 \mathrm{~K} \theta \mathrm{e}_{1000 \mathrm{hPa}}$ and suppressin of convection by MSLP both played important roles in determining the rainfall types and a switch of dominant rainfall types during the Baiu season. The feasibility of diagnosing rainfall types in terms of indices for environmental conditions was demonstrated.

Further study is needed to relate daily rain type classification with daily variations of environmental conditions, especially those for the effects of the subtropical high.

\section{Acknowledgments}

This work was partially supported by the Global Environment Research Fund (S-5) of the Ministry of the Environment, Japan, and by the TRMM Fifth Japanese Research Announcement (TRMM JRA5) by the Japan Aerospace Exploration Agency. The authors would like to express their thanks to two anonymous reviewers for their helpful comments and suggestions.

\section{References}

Chen, T.-C., S.-Y. Wang, W.-R. Huang, and M.-C. Yen, 2004: Variation of the east Asian summer monsoon rainfall. J. Climate, 17, 744-762.

Kato, T., M. Yosizaki, K. Bessho, T. Inoue, Y. Sato, and X-BAIU-01 observation group, 2003: Reason for the failure of the simulation of heavy rainfall during X-BAIU-01-Importance of a vertical profile of water vapor for numerical simulations. J. Meteor. Soc. Japan, 81, $993-$ 1013.

Kato, T., S. Hayashi, and M. Yosizaki, 2007: Statistical study on cloud top heights of cumulonimbi thermodynamically estimated form objective analysis data during the Baiu seeason. $J$. Meteor. Soc. Japan, 85, 529-557.

Moteki, Q., H. Uyeda, T. Maesaka, T. Shinoda, M. Yoshizaki, and T. Kato, 2004: Structure and development of two merged rainbands observed over the East China Sea during X-BAIU-99 Part 1 : Meso- $\beta$-scale structure and developmet processes. J. Meteor. Soc. Japan, 82, 19-44.

Moteki, Q., H. Uyeda, T. Maesaka, T. Shinoda, M. Yoshizaki, and T. Kato, 2004: Structure and development of two merged rainbands observed over the East China Sea during X-BAIU-99 Part 2: Meso- $\alpha$-scale structure and build-up processes of convergence in the Baiu forntal region. $J$. Meteor. Soc. Japan, 82, 45-65.

Ninomiya, K., 1984: Characteristics of Baiu front as a predominant subtropical front in the summer northern hemisphere. J. Meteor. Soc. Japan, 62, 880-894.

Ninomiya, K., and K. Yamazaki, 1979: Heavy rainfalls associated with frontal de-pression in Asian subtropical humid refion. (2) Mesoscale features of Precipitation, Radar echoes and stratification. J. Meteor. Soc. Japan, 57, 399-413.

Ninomiya, K., T. Akiyama, and M. Ikawa. 1988: Evolution and fine structure of a long-lived meso- $\alpha$-scale convective system in Baiu frontal zone. Part 1: Evolution and meso- $\beta$-scale characteristics. J. Meteor. Soc. Japan, 66, 331-350.

Ninomiya, K., T. Akiyama, and M. Ikawa, 1988: Evolution and fine structure of a long-lived meso- $\alpha$-scale convective system in Baiu frontal zone. Part 2: Evolution and meso- $\gamma$-scale characteristics of precipitation. J. Meteor. Soc. Japan, 66, 331-351.

Ninomiya, K., and T. Akiyama, 1992: Multi-scale features of Baiu, the summer mon-soon. J. Meteor. Soc. Japan, 70, 467-495.

Ninomiya, K., and Y. Shibagaki, 2003: Cloud system families in the Meiyu-Baiu front observed during 1-10 July 1991. J. Meteor. Soc. Japan, 81, 193-209.

Ninomiya, K., and Y. Shibagaki, 2007: Multi-scale features of the Meiyu-Baiu front and associated 
precipitation systems. J. Meteor. Soc. Japan, 85B, 103-122.

Takayabu, Y. N., 2002: Spectral representation of rain profiles and diurnal variations observed with TRMM PR over the equatorial area. Geophys. Res. Lett., 29, doi: 10.1029/2001GL014113.
Takayabu, Y. N., J. Yokomori, and K. Yoneyama, 2006: A diagnostic study on interactions between atmospheric thermodynamic structure and cumulus convection over the tropical western Pacific Ocean and over the Indochina Peninsula. J. Meteor. Soc. Japan, 84A, 151-169. 